\title{
Mencari, menemukan, dan memoles model petani ramah gambut
}

\author{
Ahmad Muhammad*, Nurul Qomar, Sigit Sutikno, Muhammad Yusa, Besri Nasrul, Arifudin, \& \\ Radith Mahatma
}

\author{
Universitas Riau \\ * aboveandbelowground@gmail.com
}

\begin{abstract}
Abstrak. Penggunaan lahan ramah gambut di bidang pertanian masih sering dipandang 'sulit,' 'menambah biaya' dan 'tidak sesuai' untuk tanaman yang dibudidayakan. Hal ini tampaknya membuat praktek-praktek penggunaan lahan yang tidak-ramah gambut sulit ditinggalkan oleh pada umumnya petani. Mereka sering menanggapi ajakan untuk mengubah cara-cara ini dengan mempertanyakan bukti. Oleh karenanya dibutuhkan bukti-bukti yang bisa meyakinkan mereka, salah satunya dalam bentuk petani ramah gambut yang berhasil yang kemungkinan bisa dianggap petani-petani lain sebagai model. Di salah satu desa di Kabupaten Siak, Provinsi Riau, baru-baru ini kami menemukan seorang petani yang berpotensi untuk dipromosikan sebagai model yang dimaksud. Meskipun demkian, setelah melakukan evaluasi secara lebih terperinci kami menjumpai sejumlah hal yang harus diperbaiki untuk meningkatkan keramahan praktek penggunaan lahan yang dilakukannya agar menjadi lebih ramah gambut. Makalah ini berkenaan dengan hasil interaksi yang terjadi antara kami dan petani tersebut dalam rangka memperbaiki: (a) pengaturan kedalaman muka air; (b) pencegahan dekomposisi gambut; (c) pencegahan subsidensi gambut; (d) penurunan emisi karbon; (e) peningkatan diversifikasi hasil kebun; (f) peningkatan kualitas estetika peragaan kebun; dan (g) peningkatan upaya promosi kunjungan dan pemasaran hasil kebun.
\end{abstract}

Kata kunci: dekomposisi gambut, diversifikasi produk, emisi karbon, estetika peragaan, promosi

\begin{abstract}
Friendly peatland utilization is often regarded as 'difficult', 'adding new cost," and 'unfavorable' to the cultivated crops. Such views appear to restrain farmers in general to adopt friendlier methods in utilizing peatlands. In response to the call for improving their practices farmers often demand proven peat-friendly but profittable practices. Therefore, convincing evidences, such as successful farmers with such practices as models, are needed. In one of villages in Siak regency, Riau Province, we encountered a farmer figure that is potentially promoted as a model in this regard. However, after evaluating what he really practiced, we found that some improvements were needed to make his practices truly peat friendlier. Our paper concerns the results of our interactions with this figure in order to improve the: (a) control of groundwater level; (b) prevention of peat decomposition; (c) prevention of peat subsidence; (d) reduction of carbon emission; (e) diversification of the farm's products; (f) aesthetic value of the farm; and (g) promotion to potential visitors and market the farm's products.
\end{abstract}

Keywords: aesthetics of display, decomposition of peat, carbon emission, diversification of products, promotion

To cite this article: Muhammad, A., N. Qomar., S. Sutikno., M. Yusa., B. Nasrul., Arifudin., \& R. Mahatma. 2020. Mencari, menemukan, dan memoles model petani ramah gambut. Unri Conference Series: Community Engagement 2: 571-576. https://doi.org/10.31258/unricsce.2.571-576

\section{(C) 2020 Authors}

Peer-review under responsibility of the organizing committee of Seminar Nasional Pemberdayaan Masyarakat 2020 


\section{PENDAHULUAN}

Salah satu sumber terpenting kerusakan gambut tropis adalah praktek-praktek pertanian yang kurang/tidak ramah gambut. Praktek-praktek seperti ini dicirikan oleh sejumlah hal, diantaranya yang terpenting adalah adanya kecenderungan memicu: (a) kekeringan gambut; (b) dekomposisi gambut dan emisi karbon; (c) subsidensi gambut; dan (d) erosi gambut. Di banyak tempat di Indonesia, teristimewa di Sumatera dan Kalimantan, praktek-praktek dengan kecenderungan seperti ini sangat lazim dijumpai (Medrilzam et al. 2017; Ude et al. 2017).

Himbauan atau ajakan kepada para petani untuk memperbaiki praktek-praktek mereka yang kurang/tidak ramah gambut seringkali ditanggapi dengan skeptis. Secara umum tampaknya terdapat persepsi di kalangan petani bahwa keharusan mereka memperbaiki praktek-praktek pertanian yang sudah biasa mereka lakukan menjadi praktek-praktek yang ramah gambut itu 'sulit' dan akan 'menambah biaya' serta 'tidak/kurang menguntungkan' bagi tanaman yang dibudidayakan. Tentu saja, persepsi ini perlu diluruskan melalui penyuluhan-penyuluhan. Meskipun demikian, pemberian informasi sejelas apapun banyak diragukan efektifitasnya dalam mengubah atau memperbaiki persepsi dan perilaku petani (Tsakok 2011). Dalam hal ini, skeptisme yang ada di kalangan para petani biasanya dapat dikikis apabila sudah ada bukti nyata yang dapat mereka jadikan contoh atau model (Taylor \& Bhasme 2018; Tsafak et al. 2015).

Bertolak dari pemikiran tersebut, kami mencoba mencari sosok di kalangan para petani sendiri yang dapat dianggap paling berpotensi untuk dijadikan model sebagaimana dimaksud. Melalui penelusuran informasi dari berbagi pihak sosok ini akhirnya dapat kami temukan, yaitu antara lain ada di DesaTeluk Merempan, Kecamatan Mempura, Kabupaten Siak, Provinsi Riau. Sosok ini dikenal dengan panggilan Pakde Indra, seorang perantau asal Jawa yang sudah hidup di kabupaten ini sejak awal tahun 1990an lalu. Informasi tentang laki-laki berumur 60 tahunan ini beserta praktek penggunaan lahannya yang relatif berskala kecil, tetapi ramah gambut dan produktif ini segera kami tindaklanjuti dengan kunjungan langsung ke kebun yang sekaligus merupakan kediaman yang bersangkutan, yang berada di tepi salah satu jalan utama menuju pusat kabupaten.

Tujuan kegiatan kami adalah: (1) mengenal profil sosok tersebut di atas dan mengevaluasi perbedaan yang ia miliki apabila dibandingkan dengan petani-petani lain pada umumnya yang telah kami kenal sebelumnya; (2) mengetahui apa saja sebenarnya yang telah dilakukannya yang dapat dikategorikan sebagai "ramah gambut"; (3) mengevaluasi (2) untuk merumuskan perbaikan-perbaikan yang dapat disusulkan kepadanya; dan (4) melihat tanggapan terhadap usulan-usulan perbaikan dan perubahan praktek yang dilakukan setelah menerima saran.

\section{METODE PENERAPAN}

Pertemuan antara kami dan petani yang kami pandang berpotensi untuk dijadikan model petani ramah gambut ini pertama kali terjadi pada bulan Agustus 2020 (dua kali), yang kemudian dilanjutkan pada bulan September (dua kali) dan Oktober 2020 (satu kali). Dalam pertemuan pertama, setelah diawali dengan perkenalan, langsung dilakukan pengamatan terhadap praktek-praktek pengelolaan lahan kebun yang dilakukan oleh yang bersangkutan. Dari hasil evaluasi terhadap apa yang telah dicatat dalam pengamatan sebelumnya, kami mengemukakan saran-saran perbaikan terhadap praktek-praktek pengelolaan lahan gambut yang telah dilakukan oleh yang bersangkutan. Dalam hal ini ada tujuh hal yang kami dorong untuk diperbaiki, yaitu: (a) pengaturan kedalaman muka air; (b) pencegahan dekomposisi gambut; (c) pencegahan subsidensi gambut; (d) penurunan emisi karbon; (e) peningkatan diversifikasi hasil kebun; (f) peningkatan kualitas estetika peragaan kebun; dan (g) peningkatan upaya promosi kunjungan dan pemasaran hasil kebun. Dalam kunjungan ketiga, kami mencoba melihat sejauh mana yang bersangkutan benar-benar bersedia melaksanakan saran-saran perbaikan yang kami berikan dalam pertemuan sebelumnya.

\section{HASIL DAN KETERCAPAIAN SASARAN}

\section{Profil sosok model}

Pakde Indra datang ke Riau pada awal tahun 1990an. Ia menyusul istrinya yang sudah lebih dahulu berangkat mengikuti keluarga kakaknya yang menjadi transmigran dan ditempatkan di afdeling 6 Desa Sialang Sakti, Kecamatan Dayun, Kabupaten Siak. Suami-istri yang berasal dari Mojokerto, Jawa Timur, yang pada waktu itu sudah beranak satu ini mengawali hidup mereka dengan menumpang, menempati satu rumah ke rumah lainnya, dan bekerja sebagai buruh harian selama bertahun-tahun. 
Pada tahun 1996 istri Pakde memutuskan berhenti bekerja sebagai buruh harian dan memulai jualan sate ayam dan sate kambing, yang ternyata cukup laris sehingga usaha ini berlanjut sampai dengan akhir tahun 2019 lalu. Pada tahun 1998, lahir anak mereka yang kedua. Pakde sendiri memutuskan untuk berhenti menjadi buruh harian dan memilih menjadi pedagang burung pekicau dan madu lebah hutan. Baik burung maupun madu ini harus ia antarkan sendiri ke Jawa, tidak jarang hingga 2-3 kali setiap bulannya, tergantung sedikitbanyaknya permintaan. Hal ini ia jalani hingga kurang lebih tahun 2014 lalu.

Pada tahun 2005 Pakde membeli lahan 2 ha di Tualang Sakti dengan uang yang sudah ia sisihkan dari tahun ke tahun. Lahan gambut yang masih berupa belukar ini ia buka dan bersihkan sendiri, sebelum akhirnya ditanami kelapa sawit. Mulai tahun 2010, ia mulai bisa menikmati hasil kebun ini sehingga keluarga ini bisa mulai membangun sebuah tempat tinggal sendiri di desa yang sama. Pakde bahkan bisa membeli sebidang lahan kebun sawit di Teluk Merempan pada tahun 2012. Pada tahun 2011 anak pertama mereka sudah menjadi sarjana, sedangkan pada tahun 2020 ini anak kedua mereka menyusul menjadi sarjana. Keduanya tamatan dari sebuah perguruan tinggi negeri di Pekanbaru.

Pakde menyatakan sangat menyukai tantangan baru. Keberhasilannya menempuh perjuangan hidup yang sangat berat selama ini membuatnya yakin bahwa kesulitan-kesulitan hidup akan dapat dihadapi dengan kesungguhan dan kerja-keras. Ia juga menyukai kemajuan-kamajuan atau "inovasi," teristimewa hal-hal yang "sederhana tetapi tepat guna." Hal ini membuatnya tak pernah berhenti mencoba berbagai hal, terutama setelah pada tahun 2012 ia mulai menggarap lahan di Teluk Merempan yang saat ini ia tempati beserta istrinya. Inovasi-inovasi ini adalah sebagaimana tersebut di bawah ini.

\section{a. Konversi kebun sawit menjadi kebun campur}

Pakde membeli sebuah kebun sawit yang pada waktu itu (2012) tanamannya sebenarnya sudah memasuki fase "buah pasir." Ternyata semua tanaman ini justru ditebangi olehnya dan kebun monokultur kelapa sawit diubahnya menjadi kebun campur.

\section{b. Penggunaan lahan gambut secara organik}

Pakde menganut prinsip "anti kimia" dan hal ini ia terapkan dengan tiga cara, yaitu: (i) hanya menggunakan pupuk organik yang ia ciptakan sendiri ramuannya; (ii) hanya mengendalikan gulma secara mekanik, tidak menggunakan herbisida untuk; dan (iii) tidak mengendalikan hama dengan pestisida.

\section{c. Diversifikasi produk kebun}

Keputusan mengkonversi kebun sawit dilanjutkan Pakde dengan menanam setidaknya 11 spesies pohon, enam spesies semak, dan 13 spesies perdu. Disamping itu, ia juga memelihara lebah kelulut (terdiri dari tiga spesies). Dengan demikian, produk kebun mengalami diversifikasi dari hanya satu (kelapa sawit) menjadi 15 jenis produk, termasuk yang berupa medium tanam dengan campuran pupuk organik ramuan Pakde sendiri.

\section{d. Diversifikasi cara pemasaran hasil kebun}

Pakde melakukan diversifikasi cara pemasaran hasil kebun, yaitu: (i) memasarkan hasil kebun tanpa diolah; dan (ii) memasarkan hasil olahan. Hasil kebun yang tidak diolah meliputi buah-buahan (apukat, buah naga, nanas, labu madu), tanaman dalam polibag (jeruk kesturi, jeruk lemon, jeruk nipis, murbai, stroberi), dan hasil tanaman empon-empon (jahe putih, jahe merah, kencur biasa, kencur hitam, kunyit biasa, kunyit putih). Hasil kebun yang diolah meliputi jeruk kesturi, jeruk lemon, kencur biasa dan jahe merah, yang dijual dalam bentuk "minuman herbal dan madu kelulut" ramuan khas Pakde Indra. Pemasaran sebagai minuman jadi ini ternyata cukup laris.

\section{Karakteristik praktek-praktek penggunaan lahan}

Kami mencari praktek pertanian berskala kecil yang produktif dan profitable, tetapi tetap ramah gambut. Dalam hal ini, kami melihat tingkat keramahan suatu praktek pertanian terhadap gambut setidaknya berdasarkan empat pertanyaan dasar ini, yaitu: (a) apakah praktek tersebut memicu kekeringan gambut?; (b) apakah praktek tersebut memicu dekomposisi gambut dan emisi karbon?; (c) apakah praktek tersebut memicu subsidensi gambut?; dan (d) apakah praktek tersebut memicu erosi gambut? Setelah melakukan pengamatan secara seksama terhadap praktek-praktek penggunaan lahan yang dilakukan Pakde, kami dapat merangkum hasilnya sebagaimana yang dapat dilihat di bawah ini (Tabel 1). 
Tabel 1. Karakteristik praktek penggunaan lahan gambut oleh Pakde Indra

\begin{tabular}{|c|c|c|}
\hline Parameter & Praktek & Dampak \\
\hline Pengaturan air & $\begin{array}{l}\text { - Hanya mengandalkan parit } \\
\text { jalan tanpa penambahan parit } \\
\text { sendiri }\end{array}$ & $\begin{array}{l}\text { - Penurunan kedalaman muka air yang signifikan } \\
\text { di dekat parit jalan, secara umum melampaui } 40 \\
\mathrm{~cm} \text {. }\end{array}$ \\
\hline $\begin{array}{l}\text { Pembudidayaan } \\
\text { tanaman }\end{array}$ & $\begin{array}{l}\text { - Kombinasi antara tanaman } \\
\text { yang berupa pohon, semak } \\
\text { berkayu dan perdu }\end{array}$ & $\begin{array}{l}\text { - Proporsi penutupan tajuk pohon relatif kecil } \\
(<40 \%) \text { karena sebagian besar bidang } \\
\text { permukaan lahan digunakan untuk budidaya } \\
\text { tanaman yang berupa semak ataupun perdu. }\end{array}$ \\
\hline Pengelolaan serasah & $\begin{array}{l}\text { - Pembersihan dan } \\
\text { pembakaran serasah }\end{array}$ & $\begin{array}{l}\text { - Pembersihan serasah terutama di kebun halaman } \\
\text { depan menyebabkan permukaan gambut } \\
\text { terpapar langsung sinar matahari sehingga } \\
\text { meningkatkan penguapan dan memicu } \\
\text { kekeringan. } \\
\text { - Pembakaran di tempat pengumpulan serasah } \\
\text { menyebabkan gambut di bawah serasah ikut } \\
\text { terbakar, sehingga melipatkan tingkat emisi } \\
\text { karbon. }\end{array}$ \\
\hline $\begin{array}{l}\text { Pengelolaan } \\
\text { sampah }\end{array}$ & $\begin{array}{l}\text { - Pembersihan dan } \\
\text { pembakaran sampah }\end{array}$ & $\begin{array}{l}\text { - Pembakaran di tempat pengumpulan serasah } \\
\text { menyebabkan gambut di bawah sampah ikut } \\
\text { terbakar, sehingga melipatkan tingkat emisis } \\
\text { karbon. }\end{array}$ \\
\hline $\begin{array}{l}\text { Penggunaan pupuk } \\
\text { organik }\end{array}$ & $\begin{array}{l}\text { - Penaburan/ pencampuran } \\
\text { pupuk organik ke medium } \\
\text { tanam }\end{array}$ & $\begin{array}{l}\text { - Penaburan/pencampuran pupuk organik ke } \\
\text { medium tanam dalam polybag tidak } \\
\text { membahayakan gambut, tetapi penaburan pupuk } \\
\text { ini secara langsung ke gambut berpotensi } \\
\text { melipatgandakan laju dekomposisi gambut, } \\
\text { sehingga melipatkan tingkat emisi karbon. }\end{array}$ \\
\hline
\end{tabular}

Berdasarkan rangkuman hasil evaluasi tersebut, kami memberikan saran-saran perbaikan berupa: (a) peningkatan jumlah pohon untuk memperluas tutupan tajuk, terutama pada bidang-bidang lahan yang cocok digunakan untuk budidaya tanaman penyuka naungan; (b) pengumpulan serasah untuk ditebarkan merata ke permukaan gambut sebagai pelindung sehingga tidak perlu dibakar; (c) pengumpulan sampah anorganik ke suatu wadah tanpa disertai pembakaran; dan (d) penghindaran penaburan pupuk organik secara langsung ke permukaan gambut, kecuali apabila permukaan gambutnya sudah ditutupi serasah terlebih dahulu.

Saran-saran tersebut kami sampaikan dengan mengacu ragam cara budidaya tanaman yang dipraktekan oleh Pakde Indra. Dari setidaknya 30 spesies tanaman yang ditanam Pakde pada lahan kebunnya, 26 spesies diantaranya ditanam langsung kedalam tanah (Tabel 2). Penaburan pupuk organik ramuan Pakde sendiri yang cukup banyak mengandung pupuk kendang (kotoran kambing) secara langsung ke permukaan gambut akan memicu aktifitas mikroorganisme dalam gambut. Apalagi dalam kondisi gambut yang aerobik karena sudah tidak lagi tergenang air, maka aktifitas ini akan menyebabkan gambut terdekomposisi dengan cepat, sehingga emisis karbonpun berlipat.

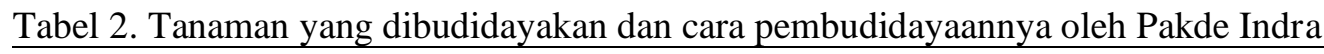

\begin{tabular}{lll}
\hline \multicolumn{1}{c}{ Bentuk/Jenis Tanaman } & Fungsi Utama & Cara Budidaya \\
\hline Pohon & & \\
\hline 1. Apukat & Penghasil buah & Ditanah langsung ke tanah \\
2. Belimbing manis & Penghasil buah & Ditanah langsung ke tanah \\
3. Jambu air & Penghasil buah & Ditanah langsung ke tanah \\
4. Jambu batu & Penghasil buah & Ditanah langsung ke tanah \\
5. Kelapa & Penghasil buah & Ditanah langsung ke tanah
\end{tabular}




\begin{tabular}{lll}
\hline \multicolumn{1}{c}{ Bentuk/Jenis Tanaman } & \multicolumn{1}{c}{ Fungsi Utama } & \multicolumn{1}{c}{ Cara Budidaya } \\
\hline 6.Nangka & Penghasil buah & Ditanah langsung ke tanah \\
7. Ketapang & Peneduh & Ditanah langsung ke tanah \\
8. Pepaya & Penghasilbuah & Ditanah langsung ke tanah \\
9. Pucuk merah & Peneduh & Ditanah langsung ke tanah \\
10. Pinang & Penghasil buah & Ditanah langsung ke tanah \\
11. Rambutan & Penghasil buah & Ditanah langsung ke tanah \\
\hline Semak & & \\
\hline 1. Airmata pengantin & Penghasil biji & Ditanah langsung ke tanah \\
2. Jeruk kesturi & Penghasil buah & Ditanam dalam polibag \\
3. Jeruk lemon & Penghasil buah & Ditanam dalam polibag \\
4. Jeruk nipis & Penghasil buah & Ditanam dalam polibag \\
5. Kopi & Penghasil biji & Ditanah langsung ke tanah \\
6. Singkong & Penghasil ubi & Ditanah langsung ke tanah \\
\hline Perdu & & \\
\hline 1. Buah naga & Penghasil buah & Ditanah langsung ke tanah \\
2. Cabe rawit & Penghasil buah & Ditanah langsung ke tanah \\
3. Jahe merah & Penghasil umbi akar & Ditanah langsung ke tanah \\
4. Jahe putih & Penghasil umbi akar & Ditanah langsung ke tanah \\
5. Kencur biasa & Penghasil umbi akar & Ditanah langsung ke tanah \\
6. Kencur hitam & Penghasil umbi akar & Ditanah langsung ke tanah \\
7. Kunyit kuning & Penghasil umbi akar & Ditanah langsung ke tanah \\
8. Kunyit putih & Penghasil umbi akar & Ditanah langsung ke tanah \\
9. Labu madu & Penghasil buah & Ditanah langsung ke tanah \\
10. Nanas & Penghasil buah & Ditanah langsung ke tanah \\
11. Pisang & Penghasil buah & Ditanah langsung ke tanah \\
12. Serai & Penghasil daun & Ditanah langsung ke tanah \\
13. Stroberi & Penghasil buah & Ditanam dalam polibag \\
\hline
\end{tabular}

\section{Perubahan pemahaman dan perilaku}

Pengabdian kepada masyarakat pada dasarnya merupakan usaha untuk menyebarluaskan ilmu pengetahuan, teknologi, dan seni kepada masyarakat. Melalui kegiatan ini diharapkan pemahaman dan perilaku masyarakat berkenaan dengan hal-hal tertentu mengalami perubahan, sehingga kualitas kehidupan masyarakat juga meningkat.

Dalam pertemuan kami yang pertama dengan Pakde, kami mencoba menelisik tentang pemahaman Pakde tentang lahan gambut dan arti penting konservasi gambut. Kami menyimpulkan bahwa ia cukup mengenal karakteristik gambut dengan cukup baik ("bersifat masam, tidak/kurang subur, bisa menyusut, bisa terbakar, asalnya tanah rawa sehingga memang basah") tetapi sebenarnya sama sekali tidak memahami arti penting konservasi gambut. Melalui pembicaraan-pembicaraan yang santai tetapi intensif, kami berkesempatan memberikan penjelasan tentang hal ini. Pakde menyatakan bisa menerima penjelasan yang kami berikan.

Dalam pertemuan-pertemuan selanjutnya, kami mulai bisa memberikan saran-saran perbaikan berdasarkan hasil evaluasi yang kami lakukan terhadap praktek-praktek penggunaan lahan kebun yang Pakde lakukan sebelumnya. Ia pun menyambut baik saran-saran yang diberikan dan berjanji akan melaksanakan sebisa mungkin. Karena Pakde berkeinginan menjadikan kebunnya sebagai tempat yang menarik untuk dikunjungi, apalagi mengingat lokasinya yang cukup strategis di tepi salah satu jalan utama kabupaten itu, maka kami pun 
menambahkan saran-saran kami tidak sekedar meliputi konservasi gambut, melainkan juga berkenaan dengan kebersihan dan kualitas estetika kebun Pakde.

Dalam kunjungan kami yang terakhir terdapat perubahan beberapa perilaku yang kami lihat pada Pakde. Perilaku tersebut meliputi: (a) pengumpulan serasah tidak untuk dibakar, melainkan dipindahkan ke suatu tempat yang disebutnya sebagai tempat pengomposan; (b) penyisaan sebagian serasah secara sengaja untuk menjadi pelindung permukaan gambut; (c) pengurangan intensitas penerapan pupuk organik secara sembarangan secara langsung ke permukaan gambut; (d) peningkatan kebersihan lingkungan dengan pengumpulan sampah-sampah anorganik ke suatu tempat; (e) penghindaran pembakaran sampah anorganik secara langsung di permukaan gambut; (f) peningkatan estetika lingkungan melalui perbaikan peragaan atau penataan produk-produk yang dipasarkan.

Perubahan-perubahan perilaku tersebut tentu saja sangat menggembirakan dan menumbuhkan optimisme kami. Meskipun demikian, kami merasa pendampingan lebih lanjut masih diperlukan untuk memantapkan sikap dan perilaku "ramah gambut" yang sudah coba dibuktikan oleh Pakde.

\section{KESIMPULAN}

Dari interaksi-interaksi yang telah terjalin dengan sosok petani yang hendak dipromosikan sebagai model petani ramah gambut, dapat disimpulkan bahwa sosok yang kami temukan ini memang sangat berpotensi untuk dipoles menjadi seorang model petani yang ramah gambut.

Sosok ini memiliki motivasi yang sangat kuat untuk menjadi pelopor dan sagat menyukai inovasi yang, meskipun bersifat sederhana, tetapi tepat guna, dan sangat terbuka terhadap informasi baru dan saran-saran.

Meskipun demikian, keberhasilan pemolesan petani ini sebagai seorang model petani ramah gambut kemungkinan akan sangat ditentukan oleh intensitas pergaulannya dengan pihak lain yang berperanan sebagai "pendorong" sebagaimana yang coba kami perankan.

\section{UCAPAN TERIMA KASIH}

Kami mengucapkan terimakasih kepada Pakde Indra beserta istri yang telah bersedia berbagi informasi dan bekerjasama dalam upaya mewujudkan model petani ramah gambut.

\section{DAFTAR PUSTAKA}

Medrilzam, C. Smith, A. Aziz, J. Herbohn \& P. Dargusch. 2017. Smallholder Farmers and the Dynamics of Degradation of Peatland Ecosystems in Central Kalimantan, Indonesia. Ecological Economics, 136, 101-113.

Uda, S.K., Hein, L. \& Sumarga, E. 2017. Towards sustainable management of Indonesian tropical peatlands. Wetlands Ecology \& Management, 25, 683-701. https://doi.org/10.1007/s11273-017-9544-0

Taylor, M. \& S. Bhasme. 2018. Model Farmers, Extension Networks and the Politics of Agricultural Knowledge Transfer. Journal of Rural Studies. 64. https://doi.org/10.1016/j.jrurstud.2018.09.015

Tsafack, S., Degrande, A., and Franzel, S., and B. Simpson. 2015. Farmer-to-Farmer Extension Approach: A survey of lead farmers in Cameroon. Working Paper 195. Nairobi, Kenya: World Agroforestry Center.

Tsakok, I. 2011. Success in agricultural transformation: What it means and what makes it happen. Makes it Happen. Success in agricultural transformation: What it means and what makes it happen. Makes it Happen https://doi.org/10.1017/CBO9781139003759 